\title{
INTEGRASI KONSEP ARSITEKTUR ISLAM PADA RUMAH ADAT SAORAJA LAPINCENG DI KABUPATEN BARRU
}

\author{
Zulkarnain AS $^{* 1}$, Andi Hildayanti ${ }^{2}$, \\ Teknik Arsitektur UIN Alauddin Makassar \\ e-mail: ${ }^{* 1}$ zoelarch@gmail.com, ${ }^{2}$ andihildayanti21@gmail.com
}

\begin{abstract}
Abstrak_ Saoraja Lapinceng merupakan salah satu rumah adat masyarakat Bugis yang terletak di Kabupaten Barru dan menjadi warisan budaya Sulawesi Selatan yang patut dijaga dan dilestarikan. Penelitian ini bertujuan untuk mengidentifikasi dan menganalisis serangkaian nilai tradisi atau filosofi yang terkandung pada Saoraja Lapinceng sebagai icon arsitektur tradisional Barru serta menemukan integrasi konsep arsitektur Islam pada rumah adat sebagai bagian upaya pelestarian budaya. Dengan menggunakan metode penelitian deskriptif, maka penelitian ini mengidentifikasi dan menemukan berbagai nilai tradisi, karakteristik komponen arsitektural, dan integrasi konsep arsitektur Islam yang diaplikasikan pada bangunan rumah adat. Hasil penelitian menunjukkan bahwa Saoraja Lapinceng memiliki karakteristik bangunan yang sama dengan rumah adat bugis pada umumnya. Disamping itu, terdapat beberapa unsur kesamaan pola ruang rumah Islami dengan pola ruang rumah tradisional Saoraja Lapinceng memberikan kaidah bahwa ajaran Islami sangat menyatu dengan karaktristik suku Bugis yang memang sangat kental dengan unsur ajaran Islami dalam kehidupan masyarakatnya
\end{abstract}

Kata kunci : Komponen Arsitektural; Rumah Adat; Konsep Arsitektur Islam; Tradisi.

\begin{abstract}
Saoraja Lapinceng is one of the traditional house of Bugis society located in Barru Regency and become cultural heritage of South Sulawesi which is women dijagai and preserved. This study aims to identify and analyze the traditional values or philosophies contained in Saoraja Lapinceng as traditional Barru architectural icons and discover the concept behind traditional Islam. By using descriptive research method, hence this research look for and find various kinds of information, characteristic of architectural component, and integrate concept of Islam architecture applied to Rumah Rumah adat. The results showed that Saoraja Lapinceng has the same building properties as custom homes bugis in general. In addition, there are several types of spatial pattern of Islamic house with the pattern of traditional home space Saoraja Lapinceng gives the rule that Islamic teachings are very united with the karaktristik Bugis tribe that is very thick with no Islamic teachings in the life of the community
\end{abstract}

Keywords : Architectural Components; Custom home; Concept of Islamic Architecture; Tradition.

\footnotetext{
${ }^{1}$ Teknik Arsitektur UIN Alauddin Makassar

${ }^{2}$ Teknik Arsitektur UIN Alauddin Makassar
} 


\section{PENDAHULUAN}

Arsitektur tradisional adalah suatu bangunan dengan bentuk, struktur, fungsi, ragam hias dan cara pembuatannya diwariskan secara turun-temurun oleh para leluhur. Arsitektur tradisional tidak terlepas dari pengaruh norma agama yang dijadikan sebagai salah satu tolok ukur dalam mendirikan bangunan. Hal ini tercermin pada filosofi-filosofi yang melekat pada bangunan tradisional seperti rumah adat. Keragaman bentuk, struktur, fungsi, dan ragam hias pada rumah adat banyak dipengaruhi oleh sistem kepercayaan, keyakinan maupun agama. Seperti halnya, bangunan Rumah Adat Saoraja Lapinceng di Kabupaten Barru yang masih berdiri kokoh hingga saat ini. Bangunan ini memiliki beberapa bentuk, struktur, dan fungsi ruang yang merepresentasikan nilai dan norma sosial, budaya, dan agama.

Pada penelitian sebelumnya yang dilakukan oleh Wasilah dan Hildayanti (2017) mengenai Filosofi Penataan Ruang Spasial Rumah Tradisional Saoraja Lapinceng Kabupaten Barru Secara Vertikal diketahui rumah tradisional ini memiliki filosofi ruang berdasarkan kerangka sosial masyarakat dan gender penghuninya. Penelitian ini hadir untuk menambah khazanah pengetahuan mengenai Rumah Adat Saoraja Lapinceng Kabupaten Barru berdasarkan kajian Islami. Mengingat mayoritas masyarakat di Kabupaten Barru, dan Indonesia secara umum beragama Islam. Sehingga perlu kiranya dilakukan kajian Islami dari salah satu situs budaya yang dimiliki.

Rumah Adat Saoraja Lapinceng berdiri diatas tanah leluhur Suku Bugis yang mayoritas beragama Islam. Oleh karena itu, penelitian ini difokuskan pada kajian integrasi Arsitektur Islam pada Rumah Adat Saoraja Lapinceng tersebut. Arsitektur Islam berprinsip pada Alquran dan Sunah (Hadis Nabi), dan menjadikan arsitektur Islam sebagai bagian integral dari Islam, yaitu "Way of life".

Merujuk pendapat Utaberta (2008), terdapat dua pendekatan untuk memahami Arsitektur Islam. Pendekatan pertama berorientasi pada objek sebagai produk masyarakat Islam, sedangkan pendekatan kedua lebih melihat pada nilai dan prinsip dasar dalam Islam. Pendekatan kedua inilah yang dikembangkan dalam penelitian ini. Penerapan nilai prinsip Islam dalam berarsitektur diharapkan mampu menjamin hubungan hablumminallah, hablumminannas, dan hablumminal'alamin. Pengaturan tersebut menghasilkan konsep arsitektur Islam yang berpijak pada Alquran dan Hadis, yang mencakup lima hal penting yaitu fungsi, bentuk, teknik, keamanan, dan kenyamanan yang kesemuanya harus mempertimbangkan kontekstualitas dan efisiensi.

Dalam konteks rumah tinggal, terdapat aturan dan arahan dari ayat Alquran dan Sunah Nabi yang membimbing aktivitas. Apabila hal tersebut dilakukan secara rutin setiap hari, hal itu akan menjadi sikap hidup atau way of life bagi orang yang melaksanakannya yang berpengaruh pada peruangan yang ditinggalinya dan berpengaruh pada perwujudan rumah tinggalnya. Nilai-nilai keIslaman pada rumah-rumah tinggal yang dibahas dalam penelitian ini adalah nilai berdasar Alquran dan Hadis, khususnya yang berkaitan dengan aktivitas dalam rumah tinggal. Islam merupakan norma untuk mengatur semua aktivitas manusia. Adapun arsitektur merupakan ruang/wadah untuk berlangsungnya aktivitas manusia sehingga dalam Islam ruang tersebut harus mampu menampung dan mengakomodasi semua aktivitas takwa (halal) dan tidak mewadahi aktivitas yang haram. Jika ruang tersebut menjadi wadah untuk aktivitas-aktivitas yang bersifat takwa, ruang tersebut dapat disebut ruang takwa. Ruang takwa ini mewadahi norma-norma absolut yang bersumber pada Alquran dan Hadis.

Penelitian ini menekankan pada kegiatan mengenali dan memahami prinsip dan nilai-nilai Arsitektur Islam yang terdapat pada Rumah Adat Saoraja Lapinceng. Mengingat rumah adat atau 
bangunan tradisional dibangun atas dasar pertimbangan alam dan prinsip keyakinan. Sebagaimana yang dijelaskan pada firman Allah Q.S. An-Nahl: 81 dan Q.S. Al-Mukminun: 29.

"Dan Allah menjadikan bagimu tempat bernaung dari apa yang telah Dia ciptakan, dan Dia jadikan bagimu tempat-tempat tinggal di gunung-gunung, dan Dia jadikan bagimu pakaian yang memeliharamu dari panas dan pakaian [baju besi] yang memelihara kamu dalam peperangan. Demikianlah Allah menyempurnakan ni'mat-Nya atasmu agar kamu berserah diri [kepada-Nya]." (Q.S. An-Nahl: 81)

"Dan berdo'alah: "Ya Tuhanku, tempatkanlah aku pada tempat yang diberkati, dan Engkau adalah sebaik-baik Yang memberi tempat." (Q.S. Al-Mukminun: 29)

Keunikan dan keindahan rumah adat menjadi daya tarik dan media pembelajaran kekayaan budaya Nusantara bagi generasi mendatang. Indonesia yang kaya akan budaya tradisional dan memiliki masyarakat yang mayoritas beragama Islam sudah sepatutnya dilakukan penelitian mengenai integrasi konsep arsitektur Islami pada fungsi rumah tinggal, dalam hal ini dimaksud adalah rumah adat. Disamping itu, wujud fisik dari representasi sistem kepercayaan atau agama pada rumah adat masih kurang dikemukakan. Keberadaannya yang masih berdiri kokoh hingga saat ini mampu menampilkan wujud dan bentuk rumah tradisional yang dibangun di masa lampau yang dibangun atas dasar sistem kepercayaan yang sangat kental. Filosofi bentuk, fungsi, dan struktur yang berlandaskan sistem kepercayaan menjadi representasi bentuk Rumah Adat Saoraja Lapinceng di Kabupaten Barru.

\section{METODOLOGI}

Penelitian ini menggunakan metode deskriptif karena dalam pelaksanaannya meliputi data, analisis dan interpretasi tentang arti dan data yang diperoleh. Penelitian ini disusun sebagai penelitian induktif yakni mencari dan mengumpulkan data yang ada di lapangan dengan tujuan untuk mengetahui faktor-faktor, unsur-unsur bentuk, dan suatu sifat dari fenomena di masyarakat.

Berangkat dari pokok permasalahan yang diangkat pada penelitian, maka metode yang dianggap sesuai dengan realitas yang ada dilapangan adalah pendekatan kualitatif dengan strategi penelitian yang digunakan adalah studi kasus dan studi sejarah arsitektural. Penelitian ini dilaksanakan melalui beberapa tahapan antara lain:

1) Observasi lapangan dan perekaman arsitektural.

2) Metode indepth interview, yang digunakan untuk pengumpulan data lapangan, yang diperoleh dari tokoh masyarakat.

3) Analisis data yang digunakan adalah teknik deskriptif eksplanatif secara kualitatif. Menurut Sugiyono (2009), yang dimaksud dengan metode deskriptif adalah metode deskriptif suatu metode dalam meneliti status sekelompok manusia, suatu objek, suatu kondisi, suatu sistem pemikiran, ataupun suatu peristiwa pada masa sekarang. Tujuan dari penelitian deskriptif ini adalah untuk membuat deskripsi, gambaran atau lukisan secara sistematis, faktual dan akurat mengenai fakta-fakta, sifat-sifat serta hubungan antar fenomena yang diselidiki.

4) Sintesis diungkapkan dalam bentuk kesimpulan dan saran.

Adapun teknik analisis yang digunakan adalah teknik analisa syncronic reading. Teknik analisa synchronic reading adalah salah satu teknik menganalisis objek penelitian melalui 
penyelarasan data observasi melalui bukti-bukti fisik maupun wawancara kepada pemangku adat atau orang yang mengetahui jejak sejarah yang terjadi pada lokasi tersebutdan data literatur. Sehingga menghasilkan berbagai deskripsi fisik rumah adat Saoraja Lapinceng berdasarkan waktu kejadiannya dalam komunikasi arsitektural yang diterjemahkan ke dalam bentuk gambar.

Gambaran korelasi antara bentuk dan ruang rumah adat Saoraja Lapinceng dengan konsep arsitektur Islamjuga diperoleh melalui teknik analisis synchronic reading yang merupakan teknik analisis membaca atau melakukan intrepetasi secara sinkron, menyelaraskan berbagai informasi yang didapatkan pada saat yang sama. (Darjosanjoto, 2006)

Analisis ini digunakan ketika seluruh teknik analisa yang lain telah rampung dikumpulkan kemudian di-sinkron-kan dan disesuaikan dengan topik penelitian. Hasil dari analisa synchronic ini merupakan rumusan bentuk korelasi integrasi tipologi rumah adat Saoraja Lapinceng dengan konsep arsitektur Islam.

\section{HASIL DAN PEMBAHASAN}

\section{A. Komponen Rumah Saoraja Lapinceng}

Rumah Saoraja Lapinceng terdiri dari 6 petak (lontang) dengan ukuran $35 \times 12$ meter dengan jumlah tiang 35 buah dengan ukuran yang berbeda-beda dikarenakan untuk menghasilkan balok yang berukuran presisi dan sama secara keseluruhan sangat sulit pada saat itu. Dalam proses pembuatan tiang hanya menggunakan parang untuk mengikis kayu bitti hingga berbentuk balok yang diinginkan. Sehingga terdapat bekas kikisan yang terlihat jelas disetiap kolom pada rumah adat Saoraja Lapinceng.

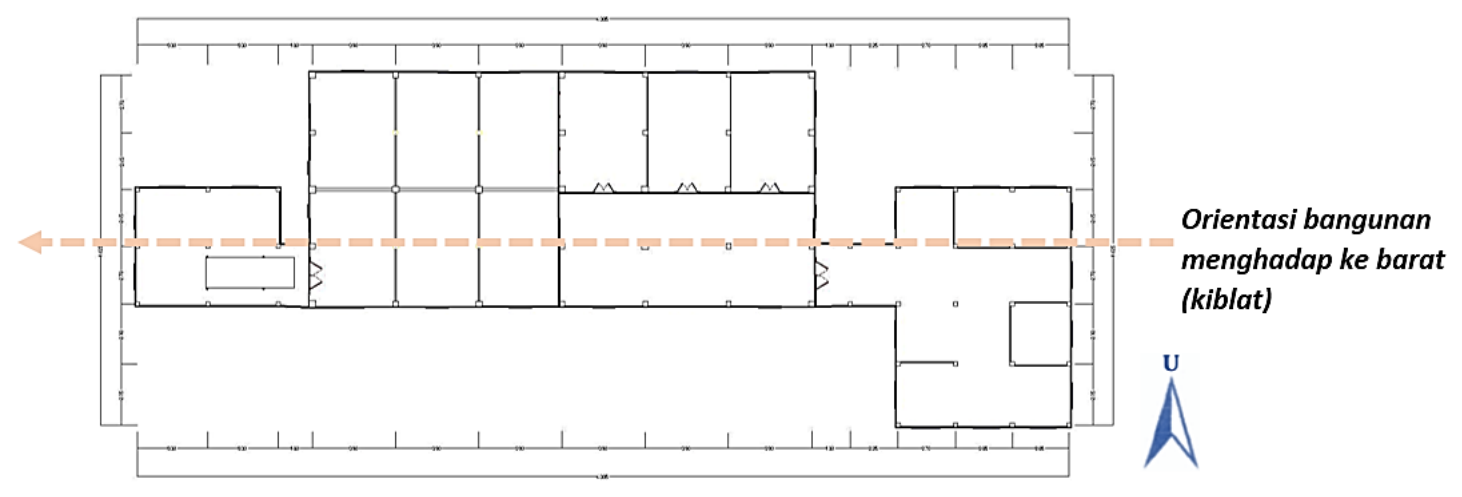

Gambar 1. Denahlantai 2Rumah Adat Saoraja Lapinceng

Saoraja Lapinceng merupakan kediaman raja di Kerajaan Balusu. Saat memasuki ruang utama rumah Saoraja Lapinceng ini memberikan kesan lapang, terlihat balok berdiri tidak sama tinggi. Balok tersebut menandakan posisi strata sosial para tamu. Potongan balok yang paling tinggi di sebelah kanan kiri raja, paling rendah di dekat ruang keluarga menuju dapur.

Pada ruang utama itu, terdapat dua buah pintu geser yang masih sangat tradisional. Salah satu pintu menuju ruang keluarga, pintu lainnya menghubungkan ruang tamu dengan kamar arajang. Memasuki ruang tengah, terdapat tiga buah kamar. Kamar arajang, raja dan selir. 


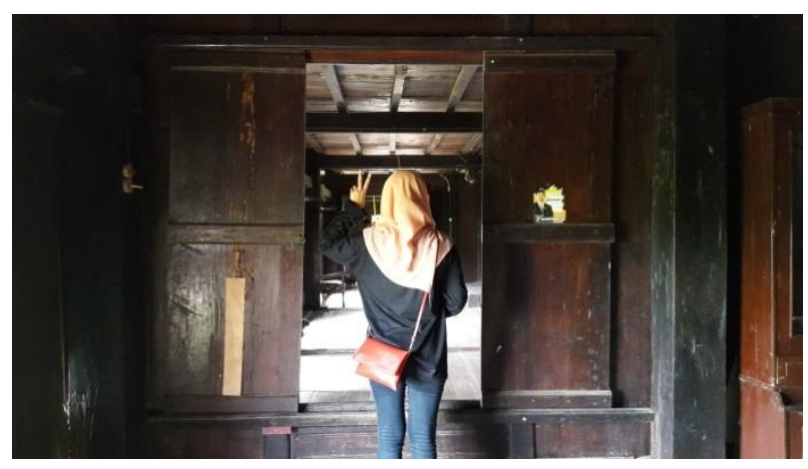

Gambar 2. Pintu yang Menghubungkan Ruang Utama dan Ruang Tengah

Secara keseluruhan, rumah Lapinceng menggunakan 35 tiang dengan 23 jendela. Tinggi rumah dari permukaan tanah sekitar 6,5 meter, dengan tinggi keseluruhan tiang mencapai 15 meter hingga pucuk atap.

Bahan bangunan utama yang banyak digunakan umumnya kayu. Bahan bangunan yang biasanya digunakan : Kayu Bitti, dan bambu.Dinding terbuat dari papan. Atap dari daun nipah. Sistem struktur menggunakan rumah panggung dengan menggunakan tiang penyangga dan menggunakan pondasi umpak. Pembuatan tiang dimulai dengan membuat posi bola (tiang pusat rumah)

Secara terinci ciri-ciri struktur rumah Saoraja Lapinceng antara lain adalah:

a. Minimal memiliki 6 petak atau 35 kolom (lima-lima).

b. Bentuk kolom adalah persegi empat.

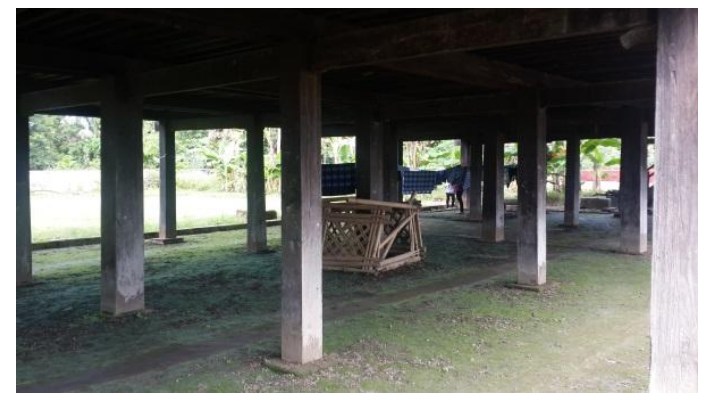

Gambar 3. Kolom Strukutur Rumah Adat Saoraja Lapinceng

c. Terdapat pusat rumah yang disebut dengan posi' bola berupa tiang yang paling penting dalam sebuah rumah, biasanya terbuat dari butti letaknya pada deretan kolom ketiga dari depan.

d. Terdapat pattolo' atau balok yang dipasang dibawah dapara (lantai). Arahnya sesuai dengan lebar rumah. Pattolo' dipasang pada kolom yang telah diubangi. Pattolo' yang telah terpasang akan diganjal dengan kayu dengan tujuan agar lebih kuat dan kaku. 
e. Selain pattolo', di rumah bugis pada umumnya juga menggunakan balok arateng, yaitu balok yang terletak diatas balok pattolo'. Namun berbeda dengan arateng pada rumah bugis pada umumnya, Saoraja Lapinceng memasang arateng tidak menembus kolom, jumlahnyapun ada 2. Pemasangan arateng mengikuti arah panjang bangunan, atau dari depan ke belakang.

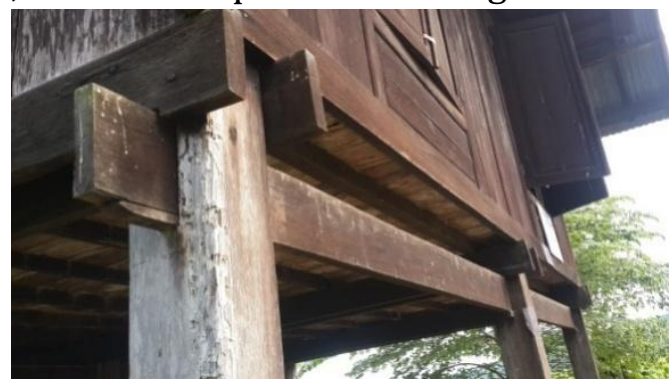

Gambar 4. Pattolo' dan arateng

Tangga diletakkan di depan atau belakang, dengan ciri-ciri:

a. Menggunakan material kayu bitti denagn anak tangga yang disusun secara rapat pada tangga utama.

b. Jumlah anak tangga selalu ganjil.

c. Memiliki pegangan tangga.

\section{Jendela}

Menurut Marwati dan Sri Andriani (2017) bahwa jendela pada rumah bugis tidak mirip antar daerah. Begitu juga jendela pada rumah saoraja Lapinceng yaitu memiliki ukuran yang besar yaitu rata-rata jendelanya besar dan lebar. Pada masa kerajaan, jendela hanya memiliki jeruji kayu yang berjumlah 5 jeruji sebagai pelindungnya tanpa meggunakan daun pintu pada jendela ini sebagai penutpnya sehinggga tampak dari luar, ruangan dalam rumah selalu terlihat oleh masyarakat setempat, sehingga pada saat hari dimana masyarakat melihat sang putri telah mendapatkan jodohnya, masyarakat akan melihat sang putri berkeliaran yang menandakan akan ada pernikahan di Saoraja Lapinceng.

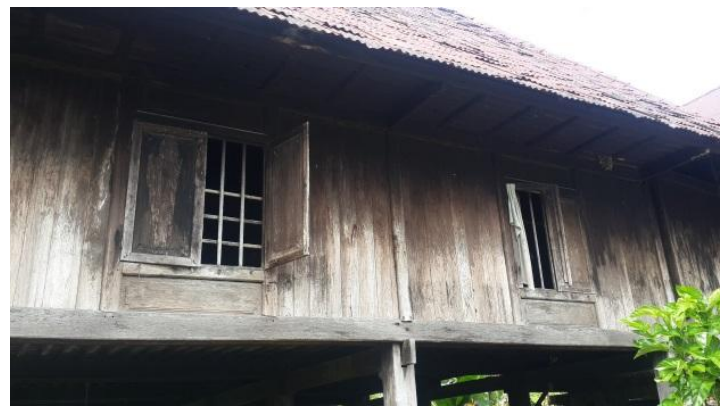

Gambar 5. Model Jendela pada Rumah Adat Saoraja Lapinceng

Dengan bukaan jendela yang cukup besar, perancang bangunan ini yang berasal dari Wajo ini berpikir bahwa aliran udara dan cahaya yang masuk dapat maksimal sehingga 
dalam rumah akan mendapatkan kenyamanan selain itu desain jendela ini dipengaruhi oleh tradisi dari suku bugis di Sulawesi Selatan yang jendelanya mirip dengan rumah tradisional seperti rumah adat Bugis Makassar dan rumah adat Gowa.

Pada tahun 1982 terjadi perbaikan besar-besaran sehingga pada saat sekarang ini jendela rumah adat Lapinceng yang kita lihat bukan lagi aslinya. Melainkan ada beberapa perubahan yaitu sudah menggukan penutup dan menggunkan beberapa material bangunan modern seperti engsel besi. Pada penutup didesain berdasarkan gaya khas Sulawesi selatan yaitu desain jendela diambil dari beberapa model pintu rumah sendiri namun ditambahkan sedikit lubang angin, dengan susunan papan kayu kecil yang disusun serong ke bawah. Sehingga desain ini sangat cocok untuk wilayah seperti di kabupaten Barru yang memiliki iklim tropis. Jadi pada saat jendela tertutup, aliran udara tetap bisa masuk.

\section{Tangga}

Terdapat 3 tangga yang digunakan pada rumah Saoraja Lapinceng, diantaranya:

\section{a. Tangga Utama}

Tangga utama memiliki 15 anak tangga, bangunan ini dibuat berdasarkan angka ganjil. Angka ganjil merupakan angka yang sakral yang dihubungkan dengan angka tuhan yaitu ganjil. Mereka percaya bahwa sesuatu yang ganjil akan digenapkan oleh Tuhan. Ini merupakan kepercayaan yang tumbuh ditengah-tengah masyarakat saat itu. Bentuk dari anak tangga utama disusun rapat dan lebar, ini berfungsi agar kuda dengan mudah naik ke teras rumah Sao Raja Lapinceng. Tangga ini terbuat dari kayu bitti dengan ukuran kayu yang cukup tebal. Kemiringan tangga dibuat tidak terlalu miring sehingga kudapun dengan mudah bisa naik ke teras. Material tangga ini hanya menggunkan kayu dan diperkuat dengan pasak kayu, namun sekitar tahun 1982 terjadi perbaikan besar besar pada bangunan ini sehingga ada beberapa material seperti pasak kayu di ganti dengan pasak besi, serta perletakan tangganya yang berasal dari batu yang disusun diganti dengan semen.

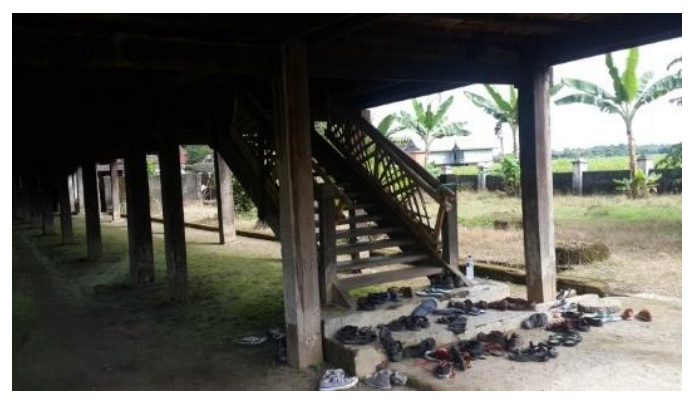

Gambar 6. Model tangga pada rumah adat Saoraja Lapinceng

Perbedaan tangga utama pada rumah adat Saoraja Lapinceng dengan rumah masyarakat biasa adalah dilihat dari posisi perletakan tangganya. Untuk rumah keturunan raja atau bangsawan posisi tangganya dipasang memanjang kedepan, namun bagi masyarakat biasa memasang tangga pada rumah mereka mengikuti lebar bangunan. 
b. Tangga Belakang Rumah

Tangga ini merupakan penghubung langsung dari bawah rumah menuju dapur. Kemiringan tangga belakang ini lebih miring dari tangga depan karena hanya diperuntuhkan untuk manusia saja, selain itu pada tangga juga dipasangi raling sebagai pegangan bagi pengguna rumah. Sedangkan jumlah anak tangga yaitu berjumlah 15 Anak tangga. Sama seperti tangga utama juga dari raling tangga belakang rumah ini beberapa materialnya sudah menggukan besi. Serta perletakannya yaitu penggunaan semen.

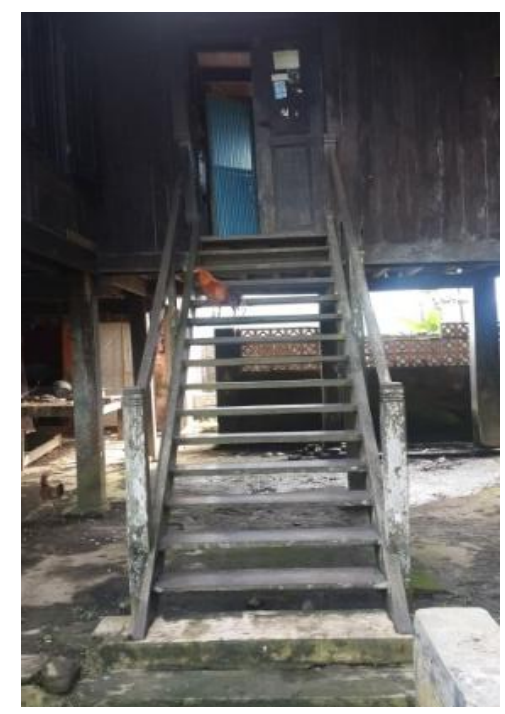

Gambar 7. Tangga belakang menuju dapur

c. Tangga tengah

Tangga ini berfungsi sebagai jalur sirkulasi menuju Loteng (rakkeang), tangga ini sangat miring yaitu sekitar 10 derajat. Tanpa di pasangi pegangan tangga. Jumlah anak tangga adalah 15.

\section{B. Integrasi Konsep Arsitektur Islam}

Selain kajian integrasi yang berkaitan dengan objek, ada juga kajian yang berhubungan dengan ide gagasan perancangan Rumah Adat Saoraja Lapinceng. Berdasarkan konsep kosmologis yang memiliki pengertian yaitu dunia yang memiliki tiga tingkatan yaitu tingkatan langit (tempat bersemayamnya dewa langit), tingkatan bumi (tempat bersemayamnya dewa bumi) dan tingkatan bawah laut. Prinsip keIslaman yang sangat sesuai dengan konsep kosmologis rumah bugis tersebut adalah Habluminallah, Habluminannas dan Habluminal'alam. Aplikasi konsep prinsip keIslaman tersebut dalam perancangan Rumah Adat Saoraja Lapinceng antara lain:

\section{Penerapan Nilai Habluminallah}

Hunian yang nyaman adalah rumah yang bisa memberikan ketenangan dan keaman bagi penghuninya atau rumah yang memenuhi kriteria rumah Islami. Secara Islami perletakan tanah atau hunian disesuaikan dengan lahan yang merupakan sarana utama dari 
suatu hunian. Tanah adalah bahan asal manusia diciptakan. Dari tanah manusia melangsungkan kehidupannya, dan di tanah pula manusia akan dimusnahkan jasadnya. Bebarapa ayat Al-Quran, baik secara tersirat atau tersurat, telah mengisyaratkan dengan ungkapan-ungkapan :

Dan memberikan tempat bagimu di bumi. Kamu diri-kan istana-istana di tanah datar-tanah datar, dan kamu pahat gunung-gunung untuk dapat didirikan atau dijadikan rumah (QS. 7:74)

Dan kami telah jadikan untuk putra Maryam beserta Ibu-nya suatu bukti nyata baginya, dan Kami melindungi mereka di suatu tempat tinggi yang datar, banyak sumber mata air yang bersih mengalir. (QS. 23:50)

Dan bumi sesudah itu dihamparkan-Nya. Ia memancarkan darinya mata airmata air, dan menumbuhkan berbagai tumbuhan. Dan gunung-gunung, dipancangkanNya dengan teguh untuk kesenanganmu dan binatang ternakmua. (QS. 79:3033).

Dari ayat-ayat Al-Quran diatas dapatlah diketahui beberapa persyaratan yang dibutuhkan dalam membangun sebuah rumah, yakni: lahan yang bersifat datar, terdapatnya sumber-sumber air bersih, tumbuh-tumbuhan dapat hidup, lahan dapat pula dijadikan areal peternakan. Penerapan Nilai Hablumminallah pada Rumah adat Saoraja Lapinceng selain pada pemilihan lahan antara lain :

a) Penempatan perabot khususnya tempat tidur dalam tradisi suku Bugis sebaiknya menghadap kiblat. Dalam rumah tradisionalBugis ruang tidur anak dan orang tua dipisahkan serta ruang tidur anak laki-laki terpisah dari ruang tidur anak perempuan.

b) Penempatan gentong air dekat dengan tangga site entrance difungsikan agar oaring yang ingin masuk rumah kakinya bersih karena dalam ajaran Islam rumah sebainya bersih, serta gentong air dapat difungsikan juga sebagai tempat mengambil air wudhu.

c) Dinding dapat dijadikan hijab untuk melaksanakan shalat.

d) Penempatan jendela-jendela yang difungsikan sebagai area pencahayaan alami agar setiap ruang dalam rumah tradisional Bugismendapatkan pencahayaan alami untuk penerangan.

e) Dalam konsep hunian Islami penempatan wc tidak bisa menghadap ke kiblat, hal ini sejalan dengan prinsip penempatan $\mathrm{km} / \mathrm{wc}$ dalam pola ruang rumah tradisional Saoraja Lapinceng karena sistem tersebut dapat dikatakan sebagai hal yang terlarang bagi unsur pemakaiannya. Ini juga telah diriwayatkan oleh Imam Bukhari dan Imam Muslim yang menjelaskan bahwa Rasulullah SAW, bersabda : "Apabila kalian buang air besar, maka janganlah menghaadp kiblat dan jangan pula membelakanginya. Akan tetapi, menghadaplah ke timur atau barat,"

\section{Penerapan Nilai Habluminannas}

Penempatan teras dibagian luar dari rumah merupakan hal yang terbaik dalam pola ruang rumah tradisional Bugis karena teras berfungsi sebagai tempat memerima tamu selain ruang tamu. Dalam tradisi suku Bugis bahwa seorang istri tidak dapat menerima 
tamu pria bila suami tidak berada di rumah maka teras dijadikan area menerima tamu tersebut. Ruang tamu dibutuhkan agar memberikan rasa nyaman dan akrab kepada tamu yang datang berkunjung.

\section{Penerapan Nilai Habluminala'alam}

Desain dan ornamen yang ada didalamnya, termasuk pemajangan patung akan tetapi unsur tumbuhan dan kaligrafi yang sebaiknya ada dalam rumah. Sesuai dengan al-Qur"anul Karim, menegaskan tentang kesadaran terhadap lingkungan dan realitas lingkungan. Hal ini terdapat dalam firman Allah SWT. "Orang-orang yang mengingat Allah sambil berdiri, duduk, atau dalam keadaan berbaring, dan mereka memikirkan tentang penciptaan langit dan bumi (seraya berkata), Ya Tuhan kami, tiadalah Engkau menciptakan ini dengan sia-sia. Maha Suci Engkau, maka peliharalah kami dari siksa neraka." (QS. Ali Imran:191).

\section{Prinsip ruang arsitektur Islam pada bangunan Sao Raja Lapinceng}

Secara garis besar bentuk denah rumah dalam konsep Islami yakni berbentuk persegi empat dimana dalam denah tersebut telah dibagi ruang-ruang yang dibutuhkan sesuai dengan syariat Islam, hal ini dapat diperhatikan pada denah rumah Khadijah alKubra dan bilik-bilik istri Rasullah SAW.
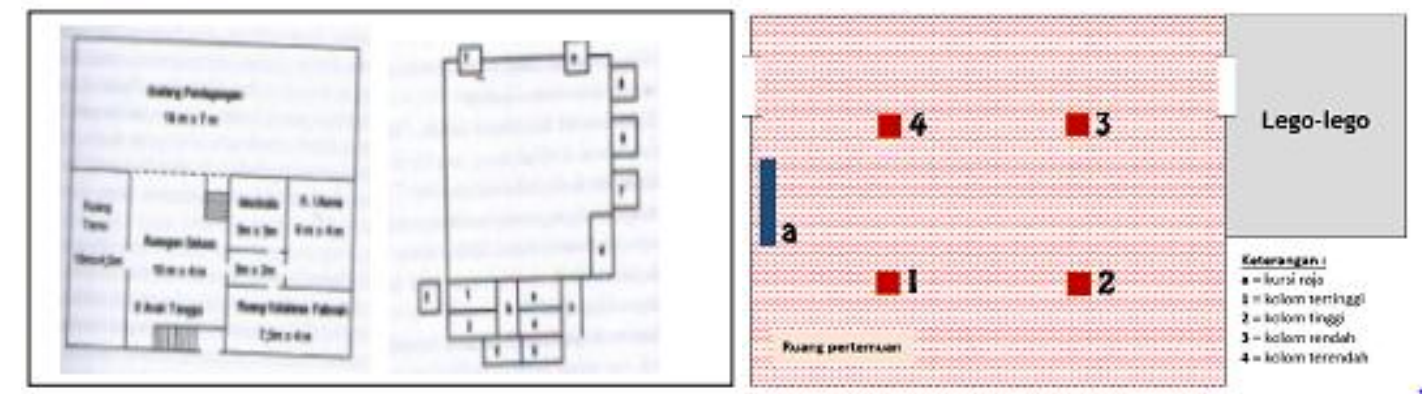

Gambar 8. (a) denah rumah Khadijah Al-kubra dan rumah Istri Rasulullah; (b) denah rumah Saoraja Lapinceng dalam Wasilah dan Hildayanti (2017)

Memperhatikan bentuk rumah Khadijah dan bilik istri Rasulullah maka ada unsur kemiripan bentuk denah dengan denah rumah tradisionalBugis yang secara garis besar berbentuk persegi empat dan memiliki ruang-ruang utama seperti ruang tidur, ruang tamu dan gudang.

Dalam Islami rumah adalah wadah atau tempat berlangsungnya proses kehidupan berumah tangga, maka rumah sebagai pembentuk kehidupan seperti:

a) Bangunan rumah secara Islami harus mempunyai ruang kamar/bilik khusus untuk ibadah. Ruang ibadah mesti berfungsi sebagai sarana ibadah yang memadai dan benar-benar berfungsi sebagai sarana yang baik, yang menghubungkan antara para penghuni rumah dengan Allah SWT. Dan hal ini Allah berfirman: "Dan Kami wahyukan kepada Musa dan saudaranya, "Ambillah olehmu berdua beberapa buah rumah di Mesir untuk tempat tinggal bagi kaummu, dan jadikanlah olehmu rumah-rumahmu itu tempat shalat. Dan, dirikanlah olehmu sembahyang, serta gembirakanlah orang-orang beriman." (QS. Yunus:87). 
b) Rumah Islami memiliki ruangan yang cukup memadai bagi penghuni rumah. Artinya, ruangan tersebut sesuai dengan kebutuhan keluarga. Dalam rumah Islami, kamar orang tua dan anak-anak terpisah. Kamar anak laki-laki dan perempuan juga terpisah satu sama lain, terutama bila sudah dewasa (baligh)."Hai orang-orang yang beriman, hendaklah budak-budak (laki-laki dan perempuan) yang kamu miliki dan orang-orang yang belum baligh di antara kamu meminta izin kepada kamu tiga kali (dalam satu hari), yaitu sebelum sembahyang subuh, ketika kamu menanggalkan pakaian (luar)mu di tengah hari, dan sesudah sembahyang Isya". (itulah) tiga "aurat bagi kamu. Tidak ada dosa atasmu dan tidak (pula) atas mereka selain dari (tiga waktu) itu. Mereka melayani kamu, sebagian kamu (ada keperluan) kepada sebagian (yang lain). Demikianlah Allah menjelaskan ayat-ayat bagi kamu. Dan, Allah Maha Mengetahui lagi Maha Bijaksana."(QS. An-Nuur:58).

c) Tersedia Kamar Tamu, hendaknya dalam membuat rumah dengan kamar yang banyak, sehingga dapat memisahkan kamar anak laki-laki dan anak perempuan. Hal ini juga mempermudah bila sewaktu-waktu ada tamu yang ingin menginap di rumah. Dan sebaiknya, kamar tamu terpisah dengan ruang keluarga sehingga tidak memungkinkan bagi tamu untuk melihat ruang keluarga secara bebas.

Adanya beberapa unsur kesamaan pola ruang rumah Islami dengan pola ruang rumah tradisional Saoraja Lapinceng memberikan kaidah bahwa ajaran Islami sangat menyatu dengan karaktristik suku Bugis yang memang sangat kental dengan unsur ajaran Islami dalam kehidupan masyarakatnya. Hal ini juga diperkuat dengan sejarah masuknya ajaran Islam ke Makassar melalui kerajaan Gowa yang merupakan daerah suku Makassar yang terbesar. Dan pada zaman kerajaan Gowa ini pula terbangun mesjid tertua di Makassar.

\section{KESIMPULAN}

Dari hasil penelitian dapat ditarik kesimpulan, bahwa Saoraja Lapinceng memiliki karakteristik bangunan yang sebagian besar menyerupai rumah adat Bugis pada umumnya. Disamping itu, terdapat beberapa unsur kesamaan pola ruang rumah Islami dengan pola ruang rumah tradisional Saoraja Lapinceng memberikan kaidah bahwa ajaran Islami sangat menyatu dengan karaktristik suku Bugis yang memang sangat kental dengan unsur ajaran Islami dalam kehidupan masyarakatnya. 


\section{DAFTAR REFERENSI}

Abdullah, H. (1985). Manusia Bugis Makassar. Jakarta : Intidayu Press.

Antoniades, Antony C. (1992). Poetic of Architecture: Theory of Design. New York: Van Nostr and Reinhold.

Creswell, J.W. (2008). Research Design: Qualitative, Quantitative, and Mixed Methods Approaches. California: Sage Publications, Inc

Daeng, H.J. (2008). Manusia, Kebudayaan dan Lingkungan, Tinjauan Antropologis. Yogyakarta : Pustaka Pelajar.

Darjosanjoto, Endang Titi Sunarti. (2012). Penelitian Arsitektur di Bidang Perumahan dan Permukiman. Surabaya : ITS press.

Groat, L. \& Wang, D. (2002). Architectural Research Methods. New York: John Wiley \& Sons. Inc.

Lang, Jon. (1994). Urban Design The American Experience. New York : Van Nostrand Reinhold.

Marwati, Sri Andriani. (2017). Tipologi Bukaan pada Rumah Tradisional Bugis di Benteng Somba Opu Makassar. Nature 4(2): 107-120.

Poerwanto, H. (2008), Kebudayaan dan Lingkungan, dalam Perspektif Antropologi, Pustaka Pelajar, Yogyakarta.

Rapoport, A. (1969). House Form and Culture. New York: Prentice-Hall, Inc, Englewood Cliffs, N.J.

Robinson, K. \& Paeni, M., (2005). Tapak-Tapak Waktu: Kebudayaan, Sejarah, dan Kehidupan Sosial di Sulawesi Selatan. Makassar : Ininnawa.

Saliya, Y. (2003). Arsitektur Sebagai Bahasa: Percobaan ke Arah Epistomologi. Perjalanan Malam Hari. Bandung: Ikatan Arsitektur Indonesia \& Lembaga Sejarah Arsitektur Indenesia.

Suparlan, Parsudi. (1999). Kemajemukan, Hipotesis Kebudayaan Dominan, dan Kesukubangsaan. Jurnal Antropologi Indonesia no.58.

Tang, Mahmud. (1996). Aneka Ragam Pengaturan Sekuritas Sosial di Bekas Kerajaan Berru, Sulawesi Selatan, ISBN 90-5485-594-0, Grafisch Service Centrum Van Gils B.V, Wageningen.

Wan Ismail, Wan Hashimah. (2012). Cultural Determinants in the Design of Bugis Houses. Journal Procedia - Social and Behavioral Sciences : Elsevier, sciencedirect, 50 (2012) 771 - 780.

Wasilah, Andi Hildayanti. (2017). Filosofi Penataan Ruang Spasial Rumah Tradisional Saoraja Lapinceng Kabupaten Barru Secara Vertikal. Jurnal RUAS 14(2) 2017:70-79.

Wasilah, Josef Prijotomo, Murni Rachmawaty. (2012). Filosofi Tipologi Bentuk dan Ekspresi Arsitektur Rumah Tradisional Mamasa, san121212. Ref No: (B.1.5)

Yunus, Pangeran Paita. (1999). Unsur-Unsur Kemahiran Lokal (Local Genius) dalam Ragam Hias Bugis: Kajian Ragam Hias pada Rumah Tradisional Bugis Sulawesi Selatan dalam UnsurUnsur Estetika Bentuk. Tesis pada Program Magister Seni Rupa dan Desain, Program Pascasarjana, Institut Teknologi Bandung, Tahun 1999.

Zulkarnain, Mutmainnah.(2017). Lokalitas Struktur dan Material Konstruksi Rumah Adat Sapo Battoa Desa Kaluppini, Kabupaten Enrekang, Sulawesi Selatan. Nature 4 (1) : 74-82. 